\title{
WAVELET BASED TECHNIQUE FOR MULTI-CRACK DETECTION OF A BEAM-LIKE STRUCTURE USING THE VIBRATION DATA MEASURED DIRECTLY FROM A MOVING VEHICLE
}

\author{
Nguyen Viet Khoa and Tran Thanh Hai \\ Institute of Mechanics, Vietnam
}

\begin{abstract}
In this paper an idea for crack detection of a multi-cracked beam-like structure by analyzing the vibration measured directly from the vehicle is presented. The crack model is adopted from fracture mechanics. The dynamic response of the bridgevehicle system is measured directly from the moving vehicle. When the vehicle moves along the structure, the dynamic response of the vehicle is distorted by the cracks at their locations. These distortions are generally small and difficult to be detected visually. In order to detect the cracks, Wavelet Transform - an effective method of detecting such small distortions was adopted. The existence of the cracks can be revealed by large values (peaks) in the wavelet transform. Locations of the cracks can be determined by positions of the peaks and the vehicle speed. Numerical results show that the method can detect cracks as small as $10 \%$ of the beam height with noise level up to $5 \%$. The proposed method is applicable for low velocity-movements while high velocity-movements are not recommended.
\end{abstract}

\section{INTRODUCTION}

The detection of cracks in mechanical systems and civil engineering structures has attracted many researchers in the last two decades as reviewed by Doebling et al. (1998). There are a large number of nondestructive methods for crack detection that are based on the changes in the dynamic properties of the structure (frequencies, mode shapes, transfer functions). Pandey et al (1991) proposed the application of mode shape curvature in detecting damage. The reduction in cross section caused by the damage tends to increase the curvature of the mode shapes in the vicinity of the damage. Verboven et al (2002, 2003) presented autonomous damage detection methods based on modal parameters. The changes in mode shapes of a slat track structure caused by the damage were auto-identified by using the frequency-domain maximum likelihood estimator method. Khoo et al (2004) presented modal analysis techniques to monitor a wooden wall structure. The significant changes in natural frequencies were used to detect the existence of damage and to identify modes that are sensitive to damage.

In the last decade, the wavelet transform has emerged as an efficient tool for signal processing due to its flexibility and precision in time and frequency resolution. Lu and Hsu 
(2002) presented a wavelet based method for detection of structural damage. The minor localized damage induced significant changes of the wavelet coefficients at the location of the damage. Poudel, Ye (2005) and Rucka, Wilde (2006) presented a wavelet-based method to localize damage in a cantilever and simply supported beam using static deflection. Recently, Castro, Garcia-Hernandez (2006) and Castro, Gallego (2006) presented a wavelet based method for defect identification in rods subject to free and forced vibration. The existence and the location of the damage caused by local changes in density or stiffness of the rod were detected by applying wavelet transform.

The analysis of continuous elastic systems subjected to moving subsystems has been a topic of interest for well over a century. Parhi and Behera (1997) presented an analytical method along with the experimental verification to investigate the vibration behavior of a cracked beam under a moving mass. Piombo et al. (2000) calculated the vehiclebridge interaction system by considering it as a three-span orthotropic plate subject to a seven degrees-of-freedom multi-body system with linear suspensions and tires flexibility. Bilello and Bergman (2004) studied damaged beams under a moving load. The damages were modeled by rotational springs whose compliance is evaluated using linear elastic fracture mechanics. Zhu and Law (2005) used continuous wavelet transform for analyzing the operational deflection time history of the bridge subject to a moving vehicular load. Most of the current methods apply dynamic responses obtained from points on the bridge for crack detection.

The aim of this study is to extend the state-of-art of structural damage detection for bridges by presenting the wavelet based technique to study the dynamic response measured directly from the moving vehicle. This is a simple method since it does not need to set up measurements on bridges. In this paper, the theoretical model of vehicle-bridge and the wavelet transform are presented. Numerical calculation has been carried out to verify the efficiency of the proposed technique.

\section{VIBRATION OF A BEAM-LIKE STRUCTURE UNDER MOVING VEHICLE}

\subsection{Intact beam}

Models of vehicles, bridges, and bridge-vehicle using for problems of moving loads on bridges were discussed by Yua and Chan (2007). The bridge-vehicle system is a very complicated system and the interaction between the bridge and the vehicle is also a complex problem influenced by a large number of different parameters. However, in some cases the models can be simplified and the use of these simplified models is more effective to establish a clear connection between the governing parameters and the bridge response than a complex model. For this purpose, we consider a specific case where the vehicle moves with low velocity so that some assumptions can be made to simplify the model of bridge-vehicle system.

We begin by considering the bridge-vehicle system shown in Fig. 1. Since the vehicle is traveling with a low velocity $v$, tyres behave in a nominally rigid manner. As a result, a one-foot vehicle model as described in Fig. 1 can be adopted. The vehicle is modelled as a single d.o.f. system with sprung (vehicle body) and unsprung (tyres) masses. The 
crack is assumed to be open all the time for the simplification purpose. The bridge deck is modelled approximately as an Euler-Bernoulli beam. The surface unevenness of the bridge is disregarded and the unsprung mass is assumed to be always in contact with the supported beam. Under these assumptions and apply the finite element method the governing equation of motion for the bridge-vehicle system can be shown as follows (Lin and Trethewey [1989]):

$$
\begin{gathered}
m_{1} \ddot{y}+c\left(\dot{y}-\dot{u}_{o}\right)+k\left(y-u_{o}\right)=0 \\
\mathbf{M} \ddot{\mathbf{d}}+\mathbf{C} \dot{\mathbf{d}}+\mathbf{K d}=\mathbf{f}=\mathbf{N}^{\mathbf{T}} f_{o} \\
f_{o}=\left(m_{1}+m_{2}\right) g-m_{2} \ddot{u}_{o}-m_{1} \ddot{y}
\end{gathered}
$$

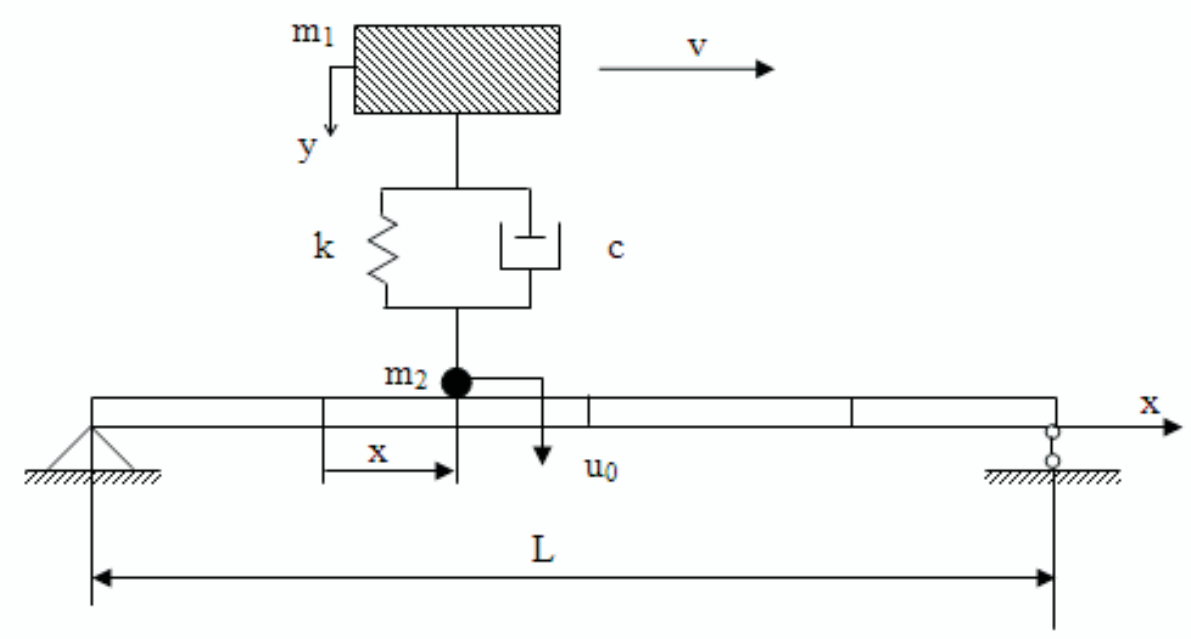

Fig. 1. A beam-like bridge under moving vehicle

Here $m_{1}, m_{2}, k, c$ are vehicle parameters as shown in Fig. $1 ; y$ denotes vertical deflection of the vehicle sprung mass $m_{1} ; u_{o}$ is the vertical deflection of $m_{2}$ and is equal to the deflection of the beam $\mathrm{u}$ at the contact position; $\mathbf{M}, \mathbf{C}, \mathbf{K}$ are structural mass, damping and stiffness matrices; $\mathbf{N}^{T}$ is the transpose of the shape functions at the position $x$ of the force; $f_{0}$ is the magnitude of the force acting on the beam; $\mathbf{d}$ is a column vector which denotes the nodal displacement of the beam. The displacement of the beam $u$ at the arbitrary position $x$ can be obtained from the shape functions $\mathbf{N}$ and the nodal displacement $\mathbf{d}$ as:

$$
u=\mathbf{N d}
$$

The shape function of an element can be obtained as:

$$
\mathbf{N}=\left[\begin{array}{llll}
N_{1} & N_{2} & N_{3} & N_{4}
\end{array}\right]
$$


where

$$
\begin{aligned}
& N_{1}=1-3\left(\frac{x}{l}\right)^{2}+2\left(\frac{x}{l}\right)^{3}, \quad N_{2}=x\left(\frac{x}{l}-1\right)^{2}, \\
& N_{3}=3\left(\frac{x}{l}\right)^{2}-2\left(\frac{x}{l}\right)^{3}, \quad N_{4}=x\left[\left(\frac{x}{l}\right)^{2}-\frac{x}{l}\right]
\end{aligned}
$$

with $l$ is the length of the element.

The time derivatives of $u_{o}$ are:

$$
\begin{gathered}
\dot{u}_{o}(x, t)=\frac{\partial u}{\partial x} \dot{x}+\frac{\partial u}{\partial t} \\
\ddot{u}_{o}(x, t)=\frac{\partial^{2} u}{\partial x^{2}} \dot{x}^{2}+2 \frac{\partial^{2} u}{\partial x \partial t} \dot{x}+\frac{\partial u}{\partial x} \ddot{x}+\frac{\partial^{2} u}{\partial t^{2}}
\end{gathered}
$$

The second term on the right side of equation (8) denotes the Coriolis acceleration since $m_{2}$ is moving along the vibrating beam. Because $\mathbf{N}$ is spatial function while $\mathbf{d}$ is time dependent, from (4) we have:

$$
\frac{\partial^{2} u}{\partial x^{2}}=\mathbf{N}_{x x} \mathbf{d}, \quad \frac{\partial u}{\partial x}=\mathbf{N}_{x} \mathbf{d}, \quad \frac{\partial^{2} u}{\partial x \partial t}=\mathbf{N}_{x} \dot{\mathbf{d}}, \quad \frac{\partial^{2} u}{\partial t^{2}}=\mathbf{N} \ddot{\mathbf{d}}
$$

where the subscript $x$ implies the differentiation with respect to $x$. Substituting (7), (8) and (9) into equations (1) and (2) yields:

$$
\begin{aligned}
\left(\begin{array}{cc}
\mathbf{M}+\mathbf{m}^{*} & \mathbf{N}^{\mathbf{T}} m_{1} \\
\mathbf{O} & m_{1}
\end{array}\right) & \left(\begin{array}{l}
\ddot{\mathbf{d}} \\
\ddot{y}
\end{array}\right)+\left(\begin{array}{cc}
\mathbf{C}+\mathbf{c}^{*} & \mathbf{O}^{\mathbf{T}} \\
-c \mathbf{N} & c
\end{array}\right)\left(\begin{array}{l}
\dot{\mathbf{d}} \\
\dot{y}
\end{array}\right)+ \\
& +\left(\begin{array}{cc}
\mathbf{K}+\mathbf{k}^{*} & \mathbf{O}^{\mathbf{T}} \\
-c \mathbf{N}_{\mathbf{x}} \dot{x}-k \mathbf{N} & k
\end{array}\right)\left(\begin{array}{l}
\mathbf{d} \\
y
\end{array}\right)=\left(\begin{array}{c}
\mathbf{N}^{\mathbf{T}}\left(m_{1}+m_{2}\right) g \\
0
\end{array}\right)
\end{aligned}
$$

where $\mathbf{O}$ is a row zero matrix, and :

$$
\mathbf{m}^{*}=m_{2} \mathbf{N}^{\mathbf{T}} \mathbf{N}, \quad \mathbf{c}^{*}=2 m_{2} \dot{x} \mathbf{N}^{\mathbf{T}} \mathbf{N}_{x}, \quad \mathbf{k}^{*}=m_{2} \dot{x}^{2} \mathbf{N}^{\mathbf{T}} \mathbf{N}_{x x}
$$

\subsection{Multi-cracked beam like structure}

Fig. 2 shows a uniform beam-like structure divided into $Q$ elements with $R$ cracks situated in $R$ different elements. It is assumed that the cracks only affect the stiffness, not affect the mass and damping coefficient of the beam. According to the principle of SaintVenant, the stress field is affected only in the region adjacent to the crack. Therefore, the element stiffness matrices of intact elements can be considered unchanged under a certain limitation of element sizes, only the element stiffness matrices of cracked elements are changed. An element stiffness matrix of a cracked element can be obtained as follows (Qian et al [1990]): Neglecting shear action, the strain energy of an element without a crack can be written as:

$$
W^{(o)}=\frac{1}{2 E I}\left(M^{2} l+M P l^{2}+\frac{P^{2} l^{3}}{3}\right)
$$

where $P$ and $M$ are the shear and bending internal forces at the right node of the element (Fig. 2). The additional stress energy of a crack has been calculated from fracture mechanics and the flexibility coefficients are obtained by a stress intensity factor in the linear 


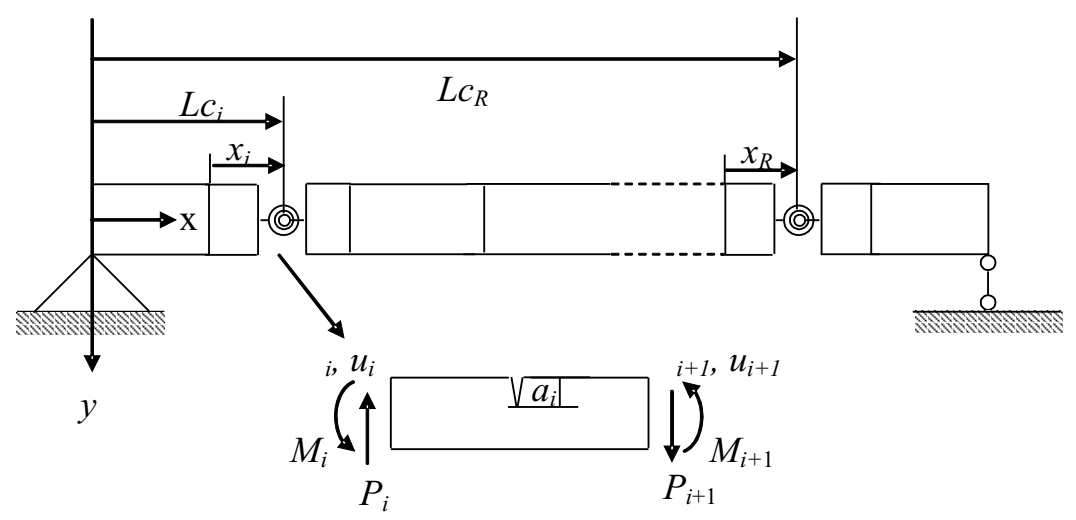

Fig. 2. Model of beam with $R$ cracks

elastic range, using Castigliano's theorem. For a rectangular beam with the thickness $h$, the width $b$, and the additional energy due to the crack can be written as

$$
W^{(1)}=b \int_{0}^{a}\left(\frac{\left(K_{I}^{2}+K_{I I}^{2}\right)}{E^{\prime}}+\frac{(1+\nu) K_{I I I}^{2}}{E}\right) d a
$$

where $E^{\prime}=E$ for plane stress, $E^{\prime}=\frac{E}{1-\nu^{2}}$ for plane strain and a is the crack depth, and $K_{I}, K_{I I}, K_{I I I}$ are stress intensity factor for opening type, sliding type and tearing type cracks, respectively.

Taking into account only bending, equation (13) leads to

$$
W^{(1)}=b \int_{0}^{a} \frac{\left(K_{I M}+K_{I P}\right)^{2}+K_{I I P}^{2}}{E^{\prime}} d a
$$

where

$$
\begin{gathered}
K_{I M}=\frac{6 M \sqrt{\pi a} F_{I}(s)}{b h^{2}}, \quad K_{I P}=\frac{3 P l \sqrt{\pi a} F_{I}(s)}{b h^{2}}, \quad K_{I I P}=\frac{P \sqrt{\pi a} F_{I I}(s)}{b h} \\
F_{I}(s)=\sqrt{\frac{2}{\pi s} \operatorname{tg}\left(\frac{\pi s}{2}\right)} \frac{0.923+0.199\left[1-\sin \left(\frac{\pi s}{2}\right)\right]^{4}}{\cos \left(\frac{\pi s}{2}\right)} \\
F_{I I}(s)=\left(3 s-2 s^{2}\right) \frac{1.122-0.561 s+0.085 s^{2}+0.18 s^{3}}{\sqrt{1-s}}
\end{gathered}
$$

where $s=a / h ; a$ is the crack depth and $h$ is the beam height.

The generic component of the flexibility matrix $\tilde{\mathbf{C}}$ of the intact element can be calculated as

$$
\tilde{c}_{i j}^{(o)}=\frac{\partial^{2} W^{(o)}}{\partial P_{i} \partial P_{j}}, i, j=1,2, P_{1}=P, P_{2}=M
$$


The additional flexibility coefficient is

$$
\tilde{c}_{i j}^{(1)}=\frac{\partial^{2} W^{(1)}}{\partial P_{i} \partial P_{j}}, i, j=1,2, P_{1}=P, P_{2}=M .
$$

Therefore, the total flexibility coefficient is:

$$
\tilde{c}_{i j}=\tilde{c}_{i j}^{(o)}+\tilde{c}_{i j}^{(1)}
$$

From the equilibrium condition the following equation can be derived

$$
\left(\begin{array}{llll}
P_{i} & M_{i} & P_{i+1} & M_{i+1}
\end{array}\right)^{T}=\mathbf{T}\left(\begin{array}{ll}
P_{i+1} & M_{i+1}
\end{array}\right)^{T},
$$

where

$$
\mathbf{T}=\left[\begin{array}{cccc}
-1 & -l & 1 & 0 \\
0 & -1 & 0 & 1
\end{array}\right]^{T}
$$

By the principle of virtual work the stiffness matrix of the cracked element can be expressed as:

$$
\mathbf{K}_{c}=\mathbf{T}^{\mathbf{T}} \tilde{\mathbf{C}}^{-1} \mathbf{T}
$$

The stiffness matrix and mass matrix for an element without a crack can be obtained as:

$$
\begin{gathered}
\mathbf{K}_{e}=\frac{E I}{l^{3}}\left[\begin{array}{cccc}
12 & 6 l & -12 & 6 l \\
6 l & 4 l^{2} & -6 l & 2 l^{2} \\
-12 & -6 l & 12 & -6 l \\
6 l & 2 l^{2} & -6 l & 4 l^{2}
\end{array}\right] \\
\mathbf{M}_{\mathbf{e}}=\frac{m l}{420}\left[\begin{array}{cccc}
156 & 22 l & 54 & -13 l \\
22 l & 4 l^{2} & 13 l & -3 l^{2} \\
54 & 13 l & 156 & -22 l \\
-13 l & -3 l^{2} & -22 l & 4 l^{2}
\end{array}\right]
\end{gathered}
$$

where $I$ is the moment of inertia; $E$ is the Young's modulus; $m$ and $l$ are the mass and the length of the element.

Element mass matrices $\mathbf{M}_{e}$ are assembled to form the global mass matrix $\mathbf{M}$, while matrices $\mathbf{K}_{e}$ and $\mathbf{K}_{c}$ are assembled to form the global stiffness matrix $\mathbf{K}$ of the cracked beam. Rayleigh damping in the form of $\mathbf{C}=\alpha \mathbf{M}+\beta \mathbf{K}$ is used for the beam. Where $\omega_{1}$ and $\omega_{2}$ are the first two bending natural frequencies of the beam, and $\alpha$ and $\beta$ are calculated as follows (Lin and Trethewey [1989]):

$$
\alpha=\frac{2 \omega_{1} \omega_{2}\left(\xi_{1} \omega_{2}-\xi_{2} \omega_{1}\right)}{\omega_{2}^{2}-\omega_{1}^{2}}, \quad \beta=\frac{2\left(\xi_{2} \omega_{2}-\xi_{1} \omega_{1}\right)}{\omega_{2}^{2}-\omega_{1}^{2}}
$$

Substituting global matrices $\mathbf{M}, \mathbf{C}$, and $\mathbf{K}$ of the cracked beam into equation (10) and solving this equation by Newmark method, the dynamic responses of the vehicle and the beam will be obtained. 


\section{WAVELET TRANSFORM}

As the name suggested, wavelet transform analysis uses small wavelike functions known as "wavelets". A more accurate description is that a wavelet is a function which has local wavelike properties. Wavelets are used to transform a signal into another form of presentation in which the signal information is presented in a more useful form. Mathematically, the wavelet transform is a convolution of the wavelet function with the signal. Generally, wavelet transform transforms signals in time (or space) domain into time (or space)-frequency domain. This means that, via wavelet transform, a signal is presented in the frequency domain while the information in time (or space) domain is still kept. This is very useful for analysing short events or sudden changes contained in signals.

\subsection{Continuous wavelet transform}

The continuous wavelet transform is defined as follows (Daubechies [1992]):

$$
W(a, b)=\frac{1}{\sqrt{a}} \int_{-\infty}^{+\infty} f(t) \psi^{*}\left(\frac{t-b}{a}\right) d t
$$

where $a$ is a real number called scale or dilation, $b$ is a real number called position, $W(a, b)$ are wavelet coefficients at scale $a$ and position $b, f(t)$ is input signal, $\psi\left(\frac{t-b}{a}\right)$ is wavelet function and $\psi^{*}\left(\frac{t-b}{a}\right)$ is complex conjugate of $\psi\left(\frac{t-b}{a}\right)$. In order to simplify the expression of the wavelet transform, denote $\psi_{a, b}(t)=\frac{1}{\sqrt{a}} \psi^{*}\left(\frac{t-b}{a}\right)$, the wavelet transform (27) can be written:

$$
W(a, b)=\int_{-\infty}^{+\infty} f(t) \psi_{a, b} d t
$$

In order to be classified as a wavelet, a function must satisfy certain mathematical criteria, they are:

1) A wavelet must have finite energy:

$$
E=\int_{-\infty}^{+\infty}|\psi(t)|^{2} d t<\infty
$$

2) If $\hat{\psi}(\omega)$ is Fourier transform of $\psi(t)$, i.e.

$$
\hat{\psi}(\omega)=\int_{-\infty}^{+\infty} \psi(t) e^{-i \omega t} d t
$$


then the following condition must be satisfied:

$$
C_{g}=\int_{0}^{\infty} \frac{|\hat{\psi}(\omega)|^{2}}{\omega} d \omega<\infty
$$

This implies that the wavelet has no zero frequency component: $\hat{\psi}(0)=0$,

$$
\int_{-\infty}^{+\infty} \psi(t) e^{-j \omega t} d t=0 \text { when } \omega=0
$$

or in other words, the wavelet must have a zero mean:

$$
\int_{-\infty}^{+\infty} \psi(t) d t=0
$$

3) An additional criterion is that, for complex wavelets, the Fourier transform must both be real and vanish for negative frequencies.

\subsection{Inverse wavelet transform}

Wavelet transform has its inverse transform:

$$
f(t)=C_{g}^{-1} \int_{-\infty}^{+\infty} \int_{-\infty}^{+\infty} W(a, b) \psi_{a, b} d b \frac{d a}{a^{2}}
$$

where

$$
C_{g}=2 \pi \int_{-\infty}^{\infty} \frac{|\hat{\psi}(\xi)|^{2}}{|\xi|} d \xi<\infty
$$

Equation (34) can be rewritten as follows:

$$
f(t)=C_{g}^{-1} \int_{-\infty}^{+\infty} a^{-2}\left[\int_{-\infty}^{+\infty} W(a, b) \psi_{a, b} d b\right] d a
$$

\section{NUMERICAL SIMULATION AND DISCUSSIONS}

A numerical example of the beam with two cracks at locations of $L c_{1}=L / 3$ and $L c_{2}=2 L / 3$ is analyzed. The crack depths of two cracks are the same. Parameters of the beam are: Mass density is $7855 \mathrm{~kg} / \mathrm{m}^{3}$; modulus of elasticity $E=1.9 \times 10^{11} \mathrm{~N} / \mathrm{m}^{2} ; L=50 \mathrm{~m}$; $b=0.5 \mathrm{~m} ; h=1 \mathrm{~m}$. Modal damping ratios for all modes are equal to 0.01 . Vehicle parameters are adopted from [27] as follows: $m_{1}=m_{2}=50000 \mathrm{~N} ; k=1.0 \times 10^{6} \mathrm{~N} / \mathrm{m} ; c=5.0 \times 10^{2} \mathrm{Ns} / \mathrm{m}$. The displacement-time history of the moving vehicle is obtained to investigate the influence of the cracks. When the beam is cracked, there are distortions in the dynamic response of the vehicle at crack locations. However, these local distortions are generally small and difficult to be detected visually. Therefore, in this work the CWT with its special property 
is applied for data processing. After trying different wavelet functions for signal processing, the wavelet function "Symlet" is chosen as the most suitable one for this study.

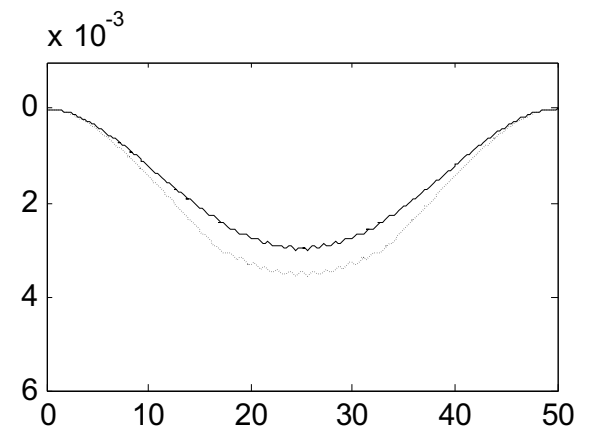

(a)

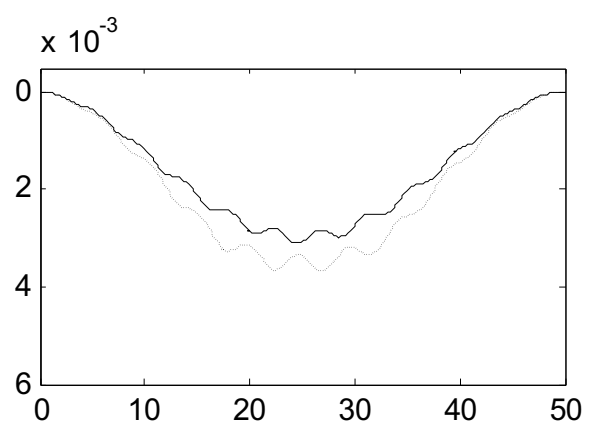

(b)

Fig. 3. Displacements of the vehicle moving on the beam with (solid lines) and without cracks (dotted lines), with different velocities: a) $v=1 \mathrm{~m} / \mathrm{s}$; b) $v=4 \mathrm{~m} / \mathrm{s}$

In this section the influence of the cracks on the dynamic response of the vehicle moving on the intact beam and the cracked beam with different crack depths is studied. Fig. 3 presents the dynamic responses of the vehicle moving at different velocities on the intact beam and the cracked beam with the crack depth of $50 \%$ of the beam height. As can be seen in this figure, with the same velocity, the dynamic response of the vehicle moving on cracked beam is greater than that of the intact beam. However, no sign of local distortions caused by cracks can be seen in this figure. This is obviously true for the case of the intact beam (solid lines), but for the cracked beam (dotted lines) this means that the local distortions in the dynamic response of the vehicle caused by the cracks is so small.

\subsection{Influence of the crack depth}

In order to detect local distortions in the dynamic response of the vehicle due to the cracks, the wavelet transform is applied. The velocity of the vehicle is $v=1 \mathrm{~m} / \mathrm{s}$. Fig. 4 shows the wavelet transform of the vertical displacement of the vehicle. As can be seen in this graph, there is no significant peaks in the wavelet transform.

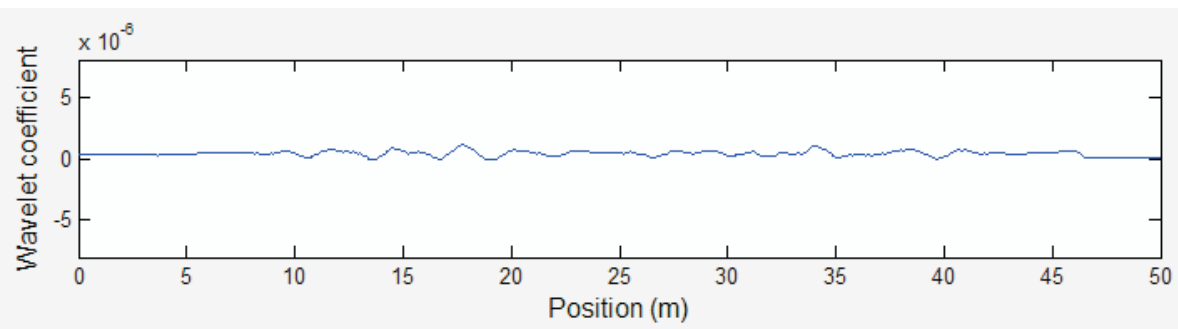

Fig. 4. Wavelet transform of $y(t)$. Crack depth is $0 \% ; v=1 \mathrm{~m} / \mathrm{s}$ 
However, when there are cracks, the wavelet transform with scale 40 shows clearly two peaks at two locations of $L / 3$ and $2 L / 3$ (see Figs. 5 to 7 ).

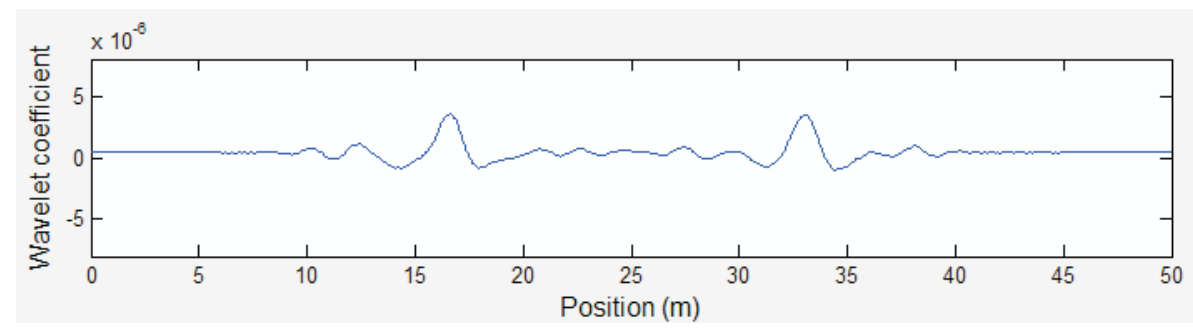

Fig. 5. Wavelet transform of $y(t)$. Crack depth is $10 \% ; v=1 \mathrm{~m} / \mathrm{s}$

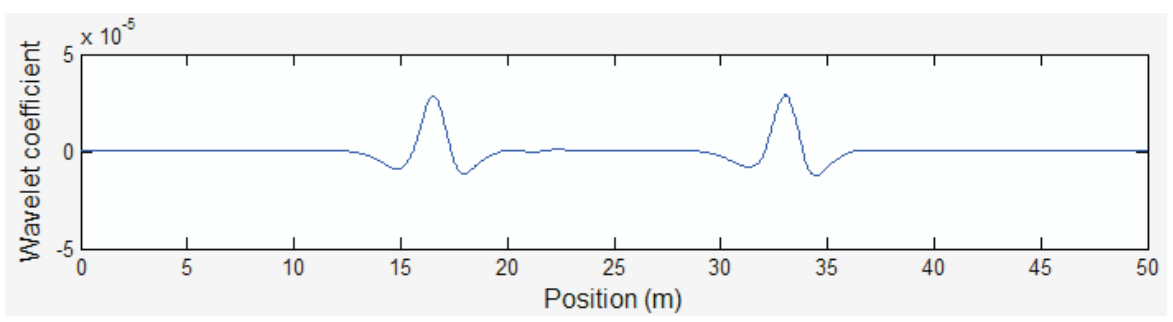

Fig. 6. Wavelet transform of $y(t)$. Crack depth is $30 \% ; v=1 \mathrm{~m} / \mathrm{s}$

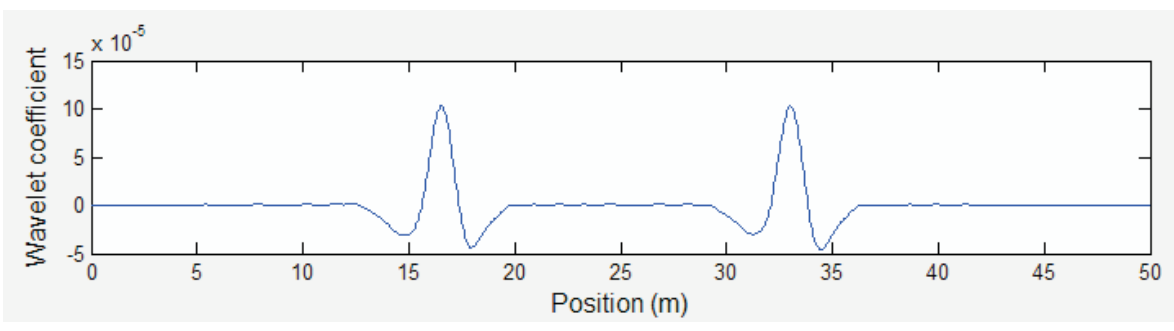

Fig. 7. Wavelet transform of $y(t)$. Crack depth is $50 \% ; v=1 \mathrm{~m} / \mathrm{s}$

The peaks of the wavelet transform explain that there are distortions in the dynamic response of the vehicle at the positions of the peaks. The locations of these peaks are at locations $L / 3$ and $2 L / 3$ of the beam, where the cracks present. This result implies that the cracks cause the distortions in the dynamic response of the vehicle at their locations, or in other words, the distortions in the dynamic response appear when the moving vehicle is passing by the crack locations. Therefore, the peaks in the wavelet transform indicate the existence of the cracks, and the positions of these peaks point out the crack locations. As can be seen in Figs. 5 to 7, when the crack depth increases from $10 \%$ to $50 \%$, the peaks at the crack positions are more significant. This means that the larger the crack depth is the more consistent of the proposed method for crack detection. 


\subsection{Influence of the noise}

In order to simulate the polluted measurements, the white noise is added to the calculated responses of the vehicle. The noisy response is calculated as following formula [Law et al, 1997]:

$$
y_{n o i s y}=y+E_{p} N \sigma(y)
$$

where $y$ is the vertical displacement of the vehicle obtained from the numerical simulation. $E_{p}$ is the noise level and $N$ is a standard normal distribution vector with zero mean value and unit standard deviation. $y_{n o i s y}$ is the noisy displacement, and $\sigma(y)$ is its standard deviation.

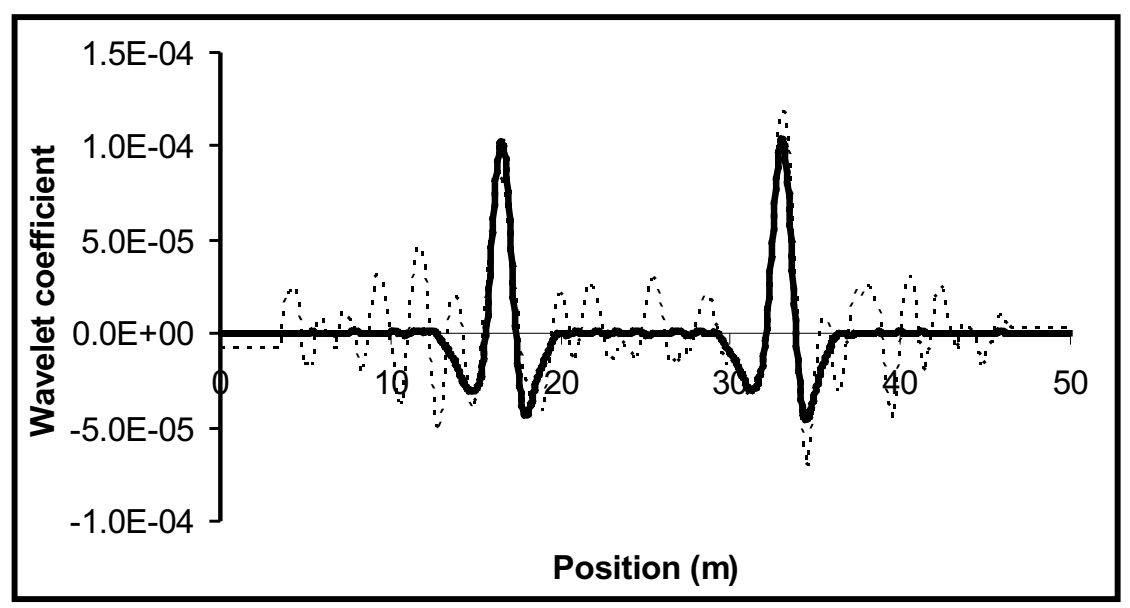

Fig. 8. Wavelet transform of dynamic responses of the vehicle, v=1 m/s. Solid line: noise level is $0 \%$; dotted line: noise level is $5 \%$

Fig. 8 show the wavelet transforms of the noisy responses of the vehicle moving on the beam with the crack depth of $50 \%$, with the velocity of $0.5 \mathrm{~m} / \mathrm{s}$. In this case, the cracks can be detected with the noise level up to $5 \%$.

\section{CONCLUSIONS}

A proposed technique for structural damage detection based on the wavelet transform of the dynamic response obtained on moving vehicle is presented.

The existence of the cracks is detected by the significant peaks in the wavelet transform of the dynamic response of the vehicle body. The crack locations can be pinpointed from the locations of the peaks in the wavelet transform and the velocity of the vehicle.

The proposed technique is simple since only one vibration transducer attached on the vehicle is needed. Also, applying the technique we do not need to consider the positions of sensors on the deck of the bridge since the vibration data is measured directly from the moving vehicle. Another advantage of the present method is that no information of the intact structure is required. Numerical results showed that the method is sensitive to cracks as small as $10 \%$ of the beam height. This method is more sensitive than frequency based methods since the natural frequencies are almost constant for cracks up to a depth 
of $50 \%$ of the beam after which they slowly decrease (Gudmunston [1983] and Nguyen [1999]).

The method can be applied for the case of non-polluted measurements as well as for the case of polluted measurements with the noise level up to $5 \%$.

From the investigation of the influence of the vehicle speed, the method works much better in comparison with the high speed.

However, the efficiency of the method has not been justified by the experiment. Therefore, to validate the presented method, experimental testing needs to be carried out as a future work.

\section{ACKNOWLEDGEMENTS}

This paper was sponsored by the National Foundation of Science and Technology Development (NAFOSTED) - Fundamental Research Project of the Department of Technical Diagnosis, Institute of Mechanics, VAST, 2009-2011.

\section{REFERENCES}

[1] Bilello C., Bergman L.A, Vibration of damaged beams under a moving mass: theory and theory and experimental validation, Journal of Sound and Vibration, 274 (2004), 567-582.

[2] Castro E., Garcia-Hernandez M. T., Gallego A., Damage detection in rods by means of the wavelet analysis of vibration: influence of the mode order, Journal of Sound and Vibration, 296 (2006), 1028-1038.

[3] Castro E., Garcia-Hernandez M. T., Gallego A., Defect Identification in rods subject to forced vibration Using the Spatial Wavelet Transform, Journal of Sound and Vibration, accepted 13 April 2006.

[4] Daubechies I., Ten lectures on wavelets, CBMS-NSF Conference series, 61. Philadelphia, PA: SISAM, (1992).

[5] Doebling S.W., Farrar C.R., Prime M.B., A summary review of vibration-based damage identification methods, The Shock and Vibration Digest, 30 (2), (1998), 91-105.

[6] Gudmundson P., The Dynamic Behaviour of Slender Structures with Cross-sectional Cracks, Journal of Mechanics Physics Solids, 31, (1983), 329-345.

[7] Khoo L. M., Mantena P. R., and Jadhav P., Structural damage assessment using vibration modal analysis, Structural Health Monitoring, 3(2), (2004), 177-194.

[8] Law S.S, Chan T.H.T, and Zeng Q.H., Moving force identification: a time domain method, Journal of Sound and Vibration, 201 (1), (1997), 1-22.

[9] Lin Y. H. and Trethewey M. W., Finite element analysis of elastic beams subjected to moving dynamic loads, Journal of Sound and Vibration, 136(2), (1989), 323-342.

[10] Lu CJ. and Hsu YT., Vibration analysis of an inhomogeneous string for damage detection by wavelet transform, International Journal of Mechanical Science, 44, (2002), 745-754.

[11] Nguyen V.K., Theoretical and experimental studies of the vibration characteristics of cracked beams, Master thesis (1999).

[12] Pandey A. K., Biswas M. and Samman M. M., Damage detection from changes in curvature mode shapes, Journal of Sound and Vibration, 145(2), (1991), 321-332.

[13] Parhi D. R. and Behera A. K. Dynamic deflection of a cracked beam with moving mass, Proc Instn Mech Engrs, 211 Part C, (1997), 77-87. 
[14] Piombo B.A.D., Fasana A., Marchesiello S., Ruzzene M., Modelling and identification of the dynamic response of a supported bridge, Mechanical Systems and Signal Processing, 14(1), (2000), 75-89.

[15] Poudel P. and Fu. G. and Ye J., Structural damage detection using digital video imaging technique and wavelet transformation, Journal of Sound and Vibration 286, (2005), 869-895.

[16] Qian G. L., Gu S. N. and Jiang J. S., The dynamic behaviour and crack detection of a beam with a crack, Journal of Sound and Vibration, 138(2), (1990), 233-243.

[17] Rucka M. and Wilde K., Crack Identification Using Wavelets on Experimental Static Deflection Profiles, Engineering Structures, 28, (2006), 279-288.

[18] Vanlanduit S., Verboven P., Guillaume P., On-line detection of fatigue cracks using an automatic mode tracking technique, Journal of Sound and Vibration, 266, (2003), 805-814.

[19] Verboven P., Parloo E., Guillaume P. and Overmeire M. V., Autonomous structural health monitoring - Part I: Modal parameter estimation and tracking, Mechanical Systems and Signal Processing, 16(4), (2002), 637-657.

[20] Verboven P., Parloo E., Guillaume P. and Overmeire M. V., Autonomous structural health monitoring - Part II: Vibration-based in-operation damage assessement, Mechanical Systems and Signal Processing, 16(4), (2002), 659-675.

[21] Yua L., Chan Tommy H.T., Recent research on identification of moving loads on bridges, Journal of Sound and Vibration, 305, (2007), 3-21.

[22] Zhu X.Q., Law S.S., Wavelet-based crack identification of bridge beam from operational deflection time history, International Journal of Solids and Structures, 43, (2006), 2299-2317.

Received July 1, 2009

\section{PHƯƠNG PHÁP WAVELET CHẨN ĐOÁN KẾT CẤU DẠNG DẦM CÓ NHIỀU VẾT NƯTT SỬ DỤNG TÍN HIỆU DAO ĐỘNG ĐO TRỰC TIẾP TRÊN XE DI ĐỘNG}

Bài báo trình bày một ý tưởng về chẩn đoán kết cấu dạng dầm có nhiều vết nứt bằng việc phân tích tín hiệu dao động đo trực tiếp trên xe di động. Mô hình vết nứt được kế thừa từ cơ học phá hủy. Phản ứng động của hệ cầu - xe được đo trực tiếp từ trên xe di động. Khi xe chuyển động dọc theo cầu thì phản ứng động của xe sẽ bị thay đổi do vết nứt gây ra tại thời điểm xe chuyển động qua vị trí của các vết nứt này. Sự thay đổi này thường nhỏ và khó phát hiện khi quan sát bằng mắt thường. Để phát hiện những vết nứt, biến đổi wavelet, một trong những phương pháp rất hiệu quả - được áp dụng để phân tích những sự thay đổi nhỏ trong phản ứng động của hệ. Sự tồn tại của vết nứt có thể được chỉ ra bởi các đỉnh có giá trị lớn bất thường trong biến đổi wavelet. Vị trí của vết nứt có thể được xác định bởi vị trí của đỉnh và vận tốc của xe. Kết quả tính toán số đã chỉ ra rằng phương pháp này có thể xác định vết nứt có độ sâu nhỏ đến $10 \%$ chiều cao của dầm với mức nhiễu lên đến $5 \%$. Phương pháp này là hiệu quả cho vận tốc xe là thấp, trong khi vận tốc xe là cao thì không cho kết quả tốt. 